\title{
Diseñar mundos virtuales: límites y hallazgos de la analítica existencial como ontología del videojuego*
}

\begin{abstract}
Resumen
Este trabajo toma como objeto principal el debate ontológico sobre el diseño de mundos virtuales. Tomando como metodología de reflexión la analítica existencial del primer Martin Heidegger, se plantea una reformulación de las relaciones entre receptor y diseñador de videojuegos, intentando superar la habitual escisión metafísica entre sujeto y objeto. Bajo nuestra lectura, el diseñador de mundos virtuales es responsable de configurar interacciones complejas - estrictamente, "plexos de entes" — de las que emerge el sentido del mundo videolúdico, tal y como quedan tematizadas dentro de la "analítica existencial" esbozada especialmente en Ser y tiempo. No obstante, nuestro trabajo también propone una lectura crítica de la aplicación de ciertos conceptos del mismo sistema: la dificultad de "diseñar muertes", la naturaleza de la angustia como un error de diseño (bug), pero ante todo la dificultad de considerar al receptor del diseño como algo más que un "videojugador" sino, antes bien, como un receptor de sentidos dados por el diseñador. Se concluye, por lo tanto, que el diseño en videojuegos depende privilegiadamente de relaciones de pragmaticidad (zeughaftigkeit) unidas en una compleja disposición funcional (bewandtnis) creadora de sentido.
\end{abstract}

\footnotetext{
* El presente trabajo ha sido realizado en el marco del proyecto de investigación El diseño narratológico en videojuegos: una propuesta de estructuras, estilos y elementos de creación narrativa de influencia postclásica (DiNaVi) (código 181369.01/1), financiado por la Universitat Jaume I, a través de la convocatoria competitiva de proyectos de investigación de la UJI, para el periodo 2019-2021.
}

\author{
Aarón Rodríguez Serrano \\ Doctor en Comunicación \\ Audiovisual \\ Profesor de la Universitat Jaume I \\ (Castellón de la Plana, España) \\ Correo electrónico: serranoa@uji.es \\ (1) orcid.org/0000-0002-3858-1045 \\ Google Scholar

\begin{abstract}
Marta Martín Núñez
Doctora en Comunicación Audiovisual

Profesora de la Universitat Jaume I (Castellón de la Plana, España).

Correo electrónico: mnunez@com.uji.es

(1) orcid.org/0000-0002-9473-1183

Google Scholar

Shaila García Catalán

Doctora en Comunicación Audiovisual

Profesora de la Univesitat Jaume I (Castellón de la Plana, España).

Correo electrónico: scatalan@uji.es ำ orcid.org/0000-0003-2508-9091

Google Scholar
\end{abstract}

Recibido: mayo 21 de 2019

Aprobado: marzo 26 de 2021

Palabras clave:

analítica existencial, diseño, mundo virtual, ontología,

videojuegos. 


\section{Designing virtual worlds: limits and findings of the existential analytics as the ontology of video games}

\begin{abstract}
This work takes as its main object the ontological debate about the design of virtual worlds. Taking Martin Heidegger's analytic reflection methodology, a reformulation of the relationships between the receiver and the video games designer is proposed trying to overcome the usual metaphysical split between subject and object. Under the reading of this work, the designer of virtual worlds is responsible for configuring complex interactions — strictly, "plexuses of entities"— from which the meaning of the video game world emerges, just as they are thematized within the "existential analytics" outlined especially in Being and Time. However, this work also proposes a critical reading of the application of certain concepts of the same system: the difficulty of "designing deaths", the nature of anguish as a design error (bug), but above all, the difficulty of considering the receiver of the design as something more than a "gamer" but, rather, as a receiver of meanings given by the designer. It is concluded, therefore, that the design in videogames depends as a privilege, on relations of pragmaticity (zeughaftigkeit) united in a complex "functional arrangement" (bewandtnis) in order to create meaning.
\end{abstract}

Key words:

Existential analytics, design, ontology, video games, virtual word. 


\section{Introducción}

El presente artículo pretende encarar desde una metodología heredada de la filosofía continental $-y$, muy concretamente, desde el programa del primer Martin Heidegger-, la problemática concreta del diseño de mundos virtuales.

Es, sin duda, una alternativa que puede sorprender en un primer momento. Si bien ya hay una buena nómina de trabajos recientes que analizan desde distintas ópticas los aspectos ontológicos de los mundos ludoficcionales (Navarrete et al., 2014; Portillo, 2017; Rodríguez, 2017b), o sus implicaciones sobre nuestra concepción del espacio urbano o íntimo (Losada, 2014; Rodríguez y Martínez, 2019) lo que aquí nos interesa es que en muchos aspectos el diseño de videojuegos desborda las "ontologías textuales" (McHale, 1987) para entrar de lleno en el problema filosófico mayor de la configuración experiencial del mundo. El complejo sistema de mundos posibles de inspiración leibniziana propuesto por Antonio José Planells (2015), la tripartición metafísica entre espacios, objetos y personajes de Siabra (2012) o la reciente contraposición entre las categorías ser y nada de Navarro (2019) son algunos de los antecedentes recientes que avalan el interés de nuestra propuesta y que supondrán, de manera privilegiada, los interlocutores hacia los que desplegaremos las siguientes páginas.

Ahora bien: ¿por qué tomar como referencia un proyecto filosófico inconcluso, e incluso para algunos autores inevitablemente frustrado (Escudero, 2017), para reflexionar precisamente sobre la manera en la que se acomete el diseño de mundos virtuales? En primer lugar, porque, a nuestro entender, la voluntad del primer Heidegger - generar una analítica existencial que no fuera concebida como una "ontología regional" y que, al mismo tiempo, superase la centralidad del sujeto o de sus posibles instancias en el proceso de habitar el mundoes algo que apenas ha sido pensado en el seno de los Game Studies. En efecto, al 
contar con una instancia real aparentemente privilegiada —el videojugador-, se han explorado con notable éxito campos como el diseño semántico de interacciones y mecánicas (Pérez, 2012), las implicaciones éticas de los textos interactivos (Frasca, 2001a) o, en el límite, los despliegues psicoanalíticos del proceso de juego (Fernández, 2015). Algunas opciones más complejas se han valido del sistema propuesto por Deleuze y Guattari (Cremin, 2016) para entender el diseño ludoficcional como una interacción de fuerzas sociales entre dos instancias colaborativas (el jugador y el diseñador) en constante proceso de territorialización.

El problema que aquí pretendemos esbozar se sitúa en una dirección ligeramente distinta e, intentando recoger algunos de los rasgos expuestos por Heidegger en sus seminarios y cursos hasta la síntesis clave realizada en Ser y tiempo en $1929^{1}$, se pregunta por la posibilidad de pensar el sentido del mundo (virtual). Sabemos que se trata abiertamente de un voluntarioso anacronismo e incluso, desde una lectura absolutamente ortodoxa, poco menos que una traición al programa del filósofo y a sus denuncias de la primacía técnica ${ }^{2}$. El diseño, entendido en su dimensión estrictamente estética (Contreras, 2019), es ya una disciplina que entraña ya la existencia de un sujeto cartesiano y que, por lo tanto, únicamente puede situarse $-y$ no sin dificultades irreconciliablesdentro del campo de las ontologías regionales. Esto implica que, siguiendo a los intérpretes más exigentes del filósofo alemán (Leyte, 2005, p. 41), pareciera más sensato dejar de lado este aparataje metodológico. Si el propio Heidegger no pudo distanciarse —al menos, durante su primera etapa- de las deudas contraídas con la herencia metafísica tradicional, ¿cómo podría hacerlo una aproximación al videojuego en la que la dualidad mundo real/mundo virtual

\footnotetext{
${ }^{1}$ A lo largo de todo el artículo utilizaremos la traducción de Jorge Eduardo Rivera (Heidegger, 2009), indicando cuando sea pertinente las matizaciones terminológicas que consideramos necesarias.

"Se pueden consultar al respecto, aunque sea de manera puramente anecdótica, sus críticas a la "cibernética" (Heidegger, 2000, p. 79 o 2013, pp. 46-54). A la contra, no está de más recordar que ha sido precisamente uno de los grandes expertos en la obra de Heidegger, Hubert Dreyfus (1992), el que con mayor inteligencia ha reflexionado sobre los límites del desarrollo de inteligencias artificiales, superando así las habituales aproximaciones propias de la filosofía computacional.
} 
se experimenta con toda crudeza? ¿No sería más sensato asumir, sin más, que la vieja distinción sujeto-objeto queda todavía más anclada en nuestra interacción con los mundos virtuales?

Ahora bien, ¿qué es lo que podemos ganar partiendo de Ser y tiempo y a la contra de su propia lectura en el campo del diseño de videojuegos? Al menos, un feliz error para entender algunos de los puntos clave que afectan a nuestra disciplina: una modificación entre las relaciones de espacio-tiempo ludoficcionales, la clarificación de lo que podría ser un mundo virtual y de lo que significaría existir en él. Huelga decir que nuestra aproximación debe ser necesariamente crítica: no pretendemos aplicar en plancha las ideas básicas de la analítica existencial al diseño interactivo sino, antes bien, mantener abiertas las fisuras y las incompatibilidades que surgen, entendiendo que en ellas también cristalizan posibles sendas de pensamiento y desarrollo. Así, comenzaremos analizando dos grandes problemas de nuestra propuesta -la función de la muerte en la constitución del Dasein, la experiencia de la angustia como elemento desvelador de la nada necesario para vivir una existencia auténtica-, y después acudiremos a aquellos terrenos que se nos antojan más fructíferos: la posibilidad de configurar un ser-en-el-mundovirtual mediante una concepción del diseño entendido en torno a dos grandes conceptos de Heidegger: el todo-de-útiles (Zeugganzen) y su disposición funcional (Bewandtnis). En este último tránsito emergerá el problema de la mundaneidad —como existenciario, pero también como elemento clave para acceder a los procesos de significatividad (Bedeutsamkeit) propios del juego.

\section{La analítica existencial como una nueva manera de entender el diseño de interacciones}

De entrada, podía señalarse que uno de los aspectos más delicados del diseño de mundos ludoficcionales pasa por la gestión de las interacciones. 
Esto no debe entenderse únicamente como una referencia a la clasificación de mecánicas o de posibles puntos de vista narrativos sino, antes bien, con todos los procesos de significación que tienen lugar mientras se recorre un mundo virtual. La diferencia frente a las "ontologías textuales" ya citadas se localiza en la constante pregunta por la manera en la que se existe dentro del videojuego, o dicho de otra manera, en la que se realiza un tránsito entre la experiencia del mundo real y la virtual.

Surge aquí la primera ventaja de tomar una aproximación basada en la analítica existencial. Frente a la tentación de pensar en términos de subjetividades - es decir, comprender las instancias virtuales como una suerte de repositorios del videojugador capaz de realizar, sublimar o simplemente reflejar una serie de rasgos más o menos conscientes en un marco lúdico-, la pregunta por el existir virtual emerge directamente hacia el concepto mismo de mundo, con toda la complejidad que dicha decisión exige. No se trata, por lo tanto, de enrocarse en los interminables - y por lo demás, cada vez menos fructíferos-debates éticos o pedagógicos sobre el funcionamiento del videojuego sino, antes bien, atender a la manera en la que el mundo virtual se muestra. El hecho mismo de que frente a nosotros se despliegue una simulación de lo real mediada por reglas y que exige un aprendizaje nos enclava en el asombro inicial ante el existir (Pardo, 2004) y nos permite tomar una posición excéntrica, distanciada, hacia el mismo.

En paralelo a las estrategias de inmersión (Frasca, 2001b; Gallastegui, 2018; Michaildis et al., 2018), el hecho de generar una suerte de epojé3 inicial sobre el trazado del mundo virtual (Husserl, 1962) permite depurar la manera en la que los procesos básicos de su despliegue van a sucederse en la experiencia ludonarrativa. Dicho con mayor claridad: el mundo, entendido como una colección de entes exterior, anterior e independiente a mi tránsito por él,

\footnotetext{
${ }^{3}$ La epojé es, al menos en la acepción fenomenológica de Husserl, un cambio radical en la manera de percibir el mundo que se caracteriza por "poner entre paréntesis" (einklammerung) tanto los prejuicios, las teorías previas, los marcos de conocimiento aparentemente ofrecidos por la realidad —y en límite, la realidad misma - para poder acceder al mundo concreto de los fenómenos tal y como se nos aparecen.
} 
queda retratado como una compleja red de relaciones que exigen ser pensadas desde una nueva mirada. Como el lector quizá comience a sospechar, nuestra propuesta es encarar el diseño ontológico del videojuego exactamente desde el punto en el que surgen las reescrituras de las grandes preguntas metafísicas a comienzos del siglo XX: la necesidad de reiniciar el asombro ante aquello que podría constituir un mundo circundante y no tanto una hipotética realidad (Eilenberger, 2019, p. 93). La pregunta por el mundo, por lo que hay (es Gibt) que se formula incluso en las lecciones de Heidegger en una fecha tan temprana como 1919 (Heidegger, 2005), requiere de un planteamiento que aplica a lo más íntimo del diseño, en tanto, como veremos, es precisamente en la acción sobre los entes donde se trenza una parte fundamental de la existencia $-\mathrm{y}$, por ende, del sentido del mundo- Pero antes de desplegar esa idea es necesario marcar también al menos dos límites, dos incompatibilidades de partida que nos obligarán a reenfocar algunos rasgos fundamentales de la analítica existencial: los problemas de la muerte y de la angustia en el videojuego.

\section{Límites de la analítica existencial en el diseño de mundos virtuales}

\section{La imposibilidad de diseñar una muerte (o el Dasein virtual)}

Desde el punto de partida mismo se dispone una gran diferencia entre la analítica existencial heideggeriana y el tránsito hacia el diseño de mundos virtuales: en principio, parece imposible encontrar un ente privilegiado sobre el que se pueda desplegar el análisis del mundo —el Dasein-, ya que la posibilidad de la muerte como horizonte ordenador de sucesos tiene una serie de rasgos característicos que, salvo ejemplos muy extremos de los que enseguida hablaremos, impiden desarrollar la diferencia entre existenciarios y categorías, así como desplegar las posteriores reflexiones entre el cuidado (Sorge), la temporalidad (Zeitlichkeit) y todo el despliegue de los éxtasis temporales. La definición de Dasein es cambiante a lo largo de la trayectoria 
de Heidegger, por lo que aquí nos valdremos exclusivamente al sentido analítico existencial propuesto en Ser y tiempo: en lugar de caer en categorías heredadas como "sujeto", "individuo", "ser humano" —que hubieran sido pertinentes para otros campos como la antropología, la filosofía del arte, el psicoanálisis...-, Heidegger se refiere en exclusiva a ese "ente que somos en cada caso nosotros mismos y que, entre otras cosas, tiene esa posibilidad de ser que es el preguntar" (Heidegger, 2009, p. 28). La pregunta por el ser, entendida en su más honda y compleja dimensión, será la que configure la presencia en el mundo del Dasein. De ahí que para un mundo virtual, de entrada, quepa preguntarse qué sería un Dasein virtual.

Es aquí donde surge el problema de las relaciones entre el sentido (en Heidegger) y la muerte. La muerte, en efecto, suele ser entendida en los videojuegos como un mecanismo propicio para el aprendizaje y la repetición (Loriguillo-López y Sorolla-Romero, 2015) o, en el límite, como una penalización inevitable que puede situar al videojugador en una posición de desventaja frente al mundo (Juul, 2013) porque no es definitiva, en la mayoría de los casos al revivir se reaparece en el último punto de guardado. Sin embargo, algunos ejemplos ofrecen matices interesantes, especialmente en el campo de las aventuras gráficas. En Until Dawn (Supermassive Games, 2015) o en Heavy Rain (Quantic Dream, 2010) el juego apuesta por una muerte definitiva del personaje-jugador, por lo que el punto de vista coral funciona para que la muerte de algunos de los personajes no sea experimentada de manera especialmente traumática en el transcurso narrativo.

Otros juegos como Hidden Agenda (Supermassive Games, 2017) optan por el camino dramático de permitir la muerte de todos los protagonistas en fases muy tempranas de la partida, de tal manera que es posible tomar decisiones ruinosas que clausuren el mundo en alrededor de media hora de juego. En el extremo opuesto, propuestas como Pokémon Let's Go! (Niantic, 2018) impiden 
explícitamente que el personaje pueda morir de ninguna manera, borrando de manera implacable la existencia de un posible horizonte de comprensión, y por ello mismo, como apuntábamos, el sentido mismo del mundo en el que se desarrolla. Este último título es un buen ejemplo para entender cómo el videojuego propone una extraordinaria escisión entre horizontes de comprensión anclados en la narrativa estructurada $a^{4}$ basados en cuestiones ónticas - el personaje principal debe vencer a sus rivales, hacerse con todas las criaturas, recorrer todos los escenarios... - frente a la vertiginosa ausencia de horizonte de comprensión del mundo virtual. Allí donde no se puede morir parece complejo que surja sentido alguno.

Diseñar una manera de morir debería entenderse aquí como planificar una manera absoluta de saber que el tránsito por el mundo virtual será único e irrepetible y, por lo tanto, que todas las acciones de interacción con el resto de los entes exigen una posición definitivamente propia, auténtica. Hay, no obstante, que contraponer dos matices. El primero es que la fundamentación de la analítica existencial sobre la muerte puede llevar a lecturas desmesuradas —en especial, sobre los discutibles elementos histórico-destinales de Ser y tiempo - que distorsionen la manera en la que el diseño del mundo se abre hacia nosotros. El segundo está magníficamente sintetizado en este fragmento de Alejandro Escudero:

La más alta posibilidad de existir no es la propia muerte [...] La más alta posibilidad se cifra en participar en el juego del saber allí dónde y cuándo en [el mundo] fraguan y se plasman obras excelentes, obras maduras, obras "clásicas", obras "originales y ejemplares" (en las ciencias o en las artes, por ejemplo); o también, allí donde el existir ejerce su inteligencia invectiva —la cima de su apertura intrínseca- cuando indaga sobre lo desconocido. (Escudero, 2017, p. 50) ${ }^{5}$

\footnotetext{
${ }^{4}$ Con narrativa estructurada nos referimos a los elementos narrativos previamente guionizados o diseñados que la agencia del jugador no puede cambiar a través de la jugabilidad. Nos referimos a los elementos narrativos clásicos vinculados al personaje, su deseo o motivación, su transformación y los acontecimientos y obstáculos que encuentra en el camino para alcanzarlo. Es un concepto equivalente al que maneja Jenkins (2004) cuando habla de "enacted narratives" (p. 124) o el diseñador narrativo Josué Monchán (2015).

${ }^{5}$ La cursiva es nuestra.
} 
Ciertamente, allí donde se introduce la cuestión del arte o del pensamiento - poesía y filosofía, los dos grandes vectores del segundo Heidegger, como veremos al final del artículo- emerge la decisiva "autenticidad" (Eigentlichkeit), esto es, llegar a ser lo más propio (eigen). Pero para ello es necesario, indudablemente, enfrentarse con el problema de la angustia.

\section{La angustia como bug ${ }^{6}$ del diseño del mundo virtual}

Resulta prudente poner al menos un pie en el parágrafo 40 de Ser y tiempo (Heidegger, 2009, pp. 202-209) para plantearse cómo el diseño de los universos videolúdicos puede verse afectado por la angustia y qué límite se desprende de dicha decisión. En primer lugar, parece claro que la función del miedo en los mundos virtuales es, a grandes rasgos, comparable a lo que ocurre en nuestra experiencia cotidiana. El ente que se utiliza para asustarme - las apariciones en The 7th guest (Trilobyte, 1993), los rivales gigantescos de Shadow of the Colossus (Team ICO, 2005)_ forman parte del mundo, son localizables. En el límite, tienen una función dentro de los hechos en los que se ordena la experiencia ludonarrativa. Otra cosa bien distinta es la angustia, que en el caso de los universos virtuales es fácilmente comparable con los bugs de diseño.

Como es bien sabido, la angustia es la condición primaria para hacerse cargo de la autenticidad —las dos siguientes serían la "silenciosa voz de la conciencia" y la "resolución ante la propia muerte" de la que hablábamos—, aunque aquí nos interesa en tanto proceso necesario para experimentar tanto la "condición de arrojado" como la irrelevancia y la caída de sentido del mundo. Los errores de diseño son, precisamente, aquellos gestos en los que la ontología del videojuego queda súbitamente desvelada y el Dasein virtual se hace consciente de los límites de la voluntad impuesta por las mecánicas del juego.

\footnotetext{
${ }^{6}$ Un bug, en el argot del diseño de videojuegos, suele hacer referencia a algún tipo de error no intencional en el proceso de desarrollo que genera una ruptura en los mecanismos de transparencia enunciativa del juego. Por ejemplo, una textura que no corresponde a la pared sobre la que se aplica, un mapa mal diseñado que lleva al jugador a trampas sin salida, errores que bloquean el funcionamiento del juego en un cierto punto...
} 
En efecto, el bug siempre interrumpe lo que parece una existencia autoclausurada y dotada del sentido narrativo — dado por la narrativa estructurada - del que hablábamos anteriormente. El bug es una erosión pura de sentido: una pared con una textura errónea, un ente que se comporta de manera inexplicable —un enemigo que se dispara a sí mismo, un ítem que no genera un efecto esperado-, una quiebra en los parámetros sobre los que se experimenta el mundo.

En cierto sentido, cuando los videojuegos utilizan los tutoriales para marcar las pautas de sentido del mundo - los efectos que se esperan de cada acción, las posibilidades de interacción con el resto de entes- están taponando, asegurando la lógica y la consistencia del mundo virtual. Están diseñando al jugador-modelo mostrando cómo funcionan las reglas del juego (game) con las que jugará (play) (Pérez, 2012, p. 52). Muy al contrario, cuando emerge el bug lo que realmente aparece es la sensación básica de haber sido realmente arrojado a un mundo incontrolable. Aunque dichos errores de diseño parezcan prácticamente infinitos, lo cierto es que son fácilmente resumibles en una topografía de "desgarros del mundo" (Lewis et al., 2016) que en el fondo no hace sino desvelar que todo universo virtual es susceptible de sufrir una orden incontrolable, una configuración interna inesperada, un proceso incomprensible de construcción de nuevas posibilidades o de súbita autodestrucción.

La diferencia entre la angustia de la analítica existencial y la de los mundos virtuales es que para el Dasein virtual resulta prácticamente imposible construir nada a partir de ella. En efecto, Heidegger planificó una experimentación de lo angustioso como una condición básica —nos atreveríamos a sugerir que incluso positiva - que sirve como condición necesaria para tomar contacto con la nada y, mediante ello, hacerse cargo del peso del proyecto propio o, tal y cómo Gianni Vattimo (1986) tradujo el complejo concepto Cuidado (sorge), un "asumir responsabilidades (en un sentido no moral)" (p. 46). A riesgo de simplificar excesivamente este proceso, lo que la angustia/bug pone de 
manifiesto en la teorización de un Dasein virtual es, precisamente, la manera en la que dicha responsabilidad está completamente inscrita en el mundo, narrativizada, pautada por una serie de normas predefinidas y que, por lo tanto, se produce un abismo en comparación con nuestra propia existencia, es decir, con la del auténtico Dasein que comparece a los mandos de control del avatar o los avatares videolúdicos.

En efecto: al quebrarse el diseño del mundo las preguntas que deberíamos formularnos no son simplemente las eminentemente metafísicas, esto es, dualistas — ¿Es mi mundo una simulación? ¿Soy yo, en tanto sujeto seguro de su existencia, preso de una ensoñación mecánica como la del mundo virtual que acaba de quebrarse? - sino, antes bien, en un nivel explícitamente ontoteológico, dar el salto desde lo virtual (la incapacidad para hacer nada que no esté predefinido por las narrativas estructuradas) hacia lo analíticoexistencial (nuestra responsabilidad, en tanto existencias arrojadas, de atravesar la angustia para volver a encarar con condiciones la pregunta por el sentido del ser). Recordemos, a modo de guía, las preguntas clave que el propio Heidegger situaba en Ser y tiempo — “ ¿Cómo es ontológicamente posible algo así como el mundo en su unidad con el Dasein? ¿De qué modo debe ser el mundo para que el Dasein pueda existir como ser-en-el-mundo?" (Heidegger, 2009, p. 380)_ o su inmediatamente posterior Introducción a la filosofía: “¿Cómo queda referido el mundo a la existencia? Y a la inversa: ¿Cómo se relaciona la existencia o Dasein con el mundo y qué significa entonces mundo?" (Heidegger, 1999, p. 253). Volveremos a ambas preguntas en el apartado "Ser-en-el-mundo-virtual".

Por el momento, si somos capaces de bordear los problemas concretos del Dasein en su relación con la muerte y la angustia, lo que emerge precisamente es el núcleo ontológico de la experiencia ludoficcional: el diseño de un posible ser-en-el-mundo mediante la interacción con los entes. Esto es: el núcleo del diseño mismo de mundos virtuales. 


\section{La posibilidad de un Dasein virtual}

Como hemos venido sugiriendo, para realizar una analítica existencial del diseño de los mundos virtuales es necesario recuperar, como condición previa, el asombro ante el mundo ludoficcional. Resulta, además, condición de máxima urgencia en tanto los dispositivos de Realidad Virtual o Realidad Aumentada parecen dispuestos a erosionar, en la medida de lo posible, las barreras que separan nuestro mundo de los diseñados artificialmente. Si bien los periféricos de última generación aplican con mayor o menor fortuna una suerte de modificación estrictamente fenomenológica (Ramírez, 2008; Trilles, 2009; Ramírez y Navarrete-Cardero, 2017) de parámetros corporales -la visión, el movimiento, el sonido...-, nosotros proponemos como paso previo la reflexión sobre la existencia misma de marcos interactivos y ficcionales generados por computadoras, ya sean inevitablemente abstractos - pongamos por caso, el interfaz que controlaba la nave en Space Invaders (Taito, 1978) — o con un alto grado de realismo inmersivo — digamos, el detalle del viento soplando a través de las cortinas en Resident Evil VII (Capcom, 2017). En ambos casos se trenza una red causal de acontecimientos en los que un ente determinado — lo que venimos Ilamando Dasein virtual_ toma una serie de acciones más o menos conscientes sobre las que se despliega una trama causal.

El diseño de videojuegos, entendido en su dimensión más estricta, consiste precisamente en la gestión de un marco más o menos explícito en el que, con base en la impostación de la libertad (Navarro, 2016) de ese ente determinado, se pueden realizar previsiones sobre los efectos causales. Acudiendo al corazón del problema, cuando generalmente se habla de videojugador para situar el centro del diseño ludonarrativo en realidad se reproduce el célebre fragmento de la segunda meditación cartesiana en el que la percepción del Otro como ser maquínico quedaba fijada en fuego en la historia de la filosofía: 
Si por acaso no mirase desde una ventana hombres que pasan por la calle, a cuya vista no dejo de decir que veo hombres [...] Y sin embargo, ¿qué veo desde la ventana sino sombreros y abrigos que pueden cubrir espectros u hombres imaginados que sólo se mueven mediante resortes? Juzgo sin embargo que son verdaderos hombres y comprendo así, por el solo poder de juzgar que reside en mi espíritu, lo que creía ver con mis ojos. (Descartes, 2011, p. 24)

En efecto, una lectura apresurada sobre el diseño de los procesos de interacción corre el riesgo de trocar sin más al anónimo viandante cartesiano por una o varias instancias ficcionales a las que, cual títeres, se les aplica en plancha la posibilidad de ser controlados —o modificados, destruidos, reconstruidos... - .

En realidad, si acuñamos la posibilidad de un Dasein virtual que se encuentre plenamente situado en el interior del universo ficcional y limitado por el mismo, somos capaces de aprehender con mucha más claridad cómo funciona el diseño ontológico de cada espacio, de cada nivel, pero ante todo, de la complejidad de las experiencias que se conjuran en su interior. Esta distinción también nos permite comprender hasta qué punto las afecciones impostadas por las tramas narrativas estructuradas de un videojuego — pongamos por caso, una historia de amor, o un trayecto heroico- dependen para su correcto despliegue no tanto de una serie de cualidades estéticas - palabra que poco sentido tiene desde la perspectiva que planteamos-, sino que se trata en realidad de hechos del mundo que únicamente pueden ser diseñados desde su interior y en el despliegue de los acontecimientos estrictamente ontológicos que los vertebran. Dicho con otras palabras: si el diseño narrativo-estructurado aparentemente simple de un Super Mario Bros funciona (si nos importa poco o nada que se trate de una princesa, un castillo, un villano con forma de dinosaurio gigante, digamos) es porque dichos elementos se perciben como plenamente fijados sobre el resto de entes del mundo: los enemigos, los ítems, el diseño de mapas y mecánicas. Para el Dasein virtual el sentido del mundo reposa, como veremos, en su capacidad para hacer experiencia en él. 
Como se puede intuir, esto marca una diferencia fundamental clave frente al videojugador, figura textual que generalmente se piensa como interpelada por los objetivos, reglas y dinámicas generalmente fijadas a elementos de narrativa estructurada: rescatar a la princesa, derrotar al villano, sobrevivir, conquistar. Antes bien, y tal y cómo Heidegger ya sugirió en sus primeros textos ontológicos desde el Informe Natorp (Heidegger, 2002), lo que interpela al Dasein - y no al "sujeto de la metafísica convencional" — es el mundo mismo, el sentido de la porción del mundo en la que habita, y sobre la que proyecta - de manera generalmente "inauténtica" o en relación con el estado-de-yecto o la caída (Verfallenheit) — una serie de velos mediante los que zafarse de la verdadera problemática que implica estar-ahí.

Curiosamente, es precisamente cuando la narrativa estructurada se niega a ofrecer una meta clara cuando emerge con toda claridad la posibilidad de un Dasein virtual en oposición a un videojugador. Tomemos como ejemplo The Stanley Parable (Davey Wreden y Galactic Cafe, 2013). Prácticamente desde los primeros minutos de juego parece evidente que no hay una misión que acometer, un logro que desbloquear o un villano al que vencer. Pese a las diferentes instancias narrativas, el sentido del mundo virtual no es resumible en una mecánica concreta. Si tomamos Tetris (Aleksei Pàjitnov y Vladimir Pokhilko, 1984) como el ejemplo habitual de sentido mediante mecánica —el videojugador debe sobrevivir mediante una correcta alineación de figuras prefijadas-, The Stanley Parable va un paso más lejos y bloquea completamente la idea de que el sentido del mundo está en manos de un diseñador o de un videojugador. Al contrario, es el Dasein virtual el que, incapaz de vencer o de ser derrotado, recorre los espacios siendo problematizado por el mundo, siendo únicamente interpelado por la pregunta clave: ¿Qué es este aqui?

Llegados a este punto, parece claro que la analítica trascendental cobra un nuevo interés en el diseño de videojuegos al sugerirnos, al menos, dos áreas 
de reflexión: la primera es la necesidad de replantearnos el espacio y el tiempo como dos variables razonablemente independientes fundamentadas a su vez por grados de duración o de extensión. La segunda sería intentar saber cómo funciona ese ente privilegiado y al que podríamos referir, al menos por el momento, a la expresión ser-en-el-mundo-virtual.

\section{Diseñar el espacio y el tiempo virtuales}

Comenzando por la primera parece sensato señalar cómo el diseño de mundo virtuales ha puesto en serios problemas la manera en la que los sistemas categoriales kantianos habían gestionado las dimensiones espacio y tiempo $-y$, todo sea dicho, generalmente mediante una subordinación implícita del primero al segundo (Escudero, 2013)_. Esto tiene que ver, por ejemplo, con la manera en la que ciertas mecánicas de interacción se basan, ante todo, en la ruptura de la conexión de ambas variables en el mundo virtual. Por ejemplo, en SuperHOT (SUPERHOT Team, 2016) el tiempo avanza o retrocede sin ningún tipo de linealidad, sometiéndose en exclusiva a las interacciones del Dasein Virtual. En algunos de los juegos diseñados por Hidetaka Miyazaki — por ejemplo, la saga Dark Souls o Bloodborne (From Software, 2015) — se trazan extrañas líneas entre la detención del tiempo, su superposición, su repetición o su negación. El Dasein virtual puede encarnar de manera paralela el mismo tiempo en distintos espacios — por ejemplo, con las líneas de personaje múltiple que se cruzan en Detroit: Become Human (Quantic Dream, 2018) — o, a la inversa, regresar a espacios congelados que parecen pertenecer a tiempos únicos extraídos de alguna manera del continuo diegético —es el caso de la zona de reposo en The Evil Within 2 (Tango Gameworks, 2017)_. El límite de estas argumentaciones se encuentra, por supuesto, en el diseño de narrativas procedurales y su capacidad para extenderse prácticamente hasta el infinito mediante la generación de tiempos y espacios absolutamente aleatorios y prácticamente inagotables. 
Esto, sin embargo, no implica que una parte importante de las narrativas estructuradas que sirven como base al diseño de mundos sigan todavía al menos dos parámetros ontológicos heredados o bien del clasicismo audiovisual —mundos autónomos, lineales, clausurados y dominados por una suerte de transparencia enunciativa一, o bien, lo que aquí nos interesa mucho más, por una concepción del espacio-tiempo propiamente moderna, esto es, anterior a las aportaciones heideggerianas al respecto. Quizá podamos encontrar el ejemplo más radical en los Ilamados God Games (Gil y Rodríguez, 2017). En ellos, la problemática del hay (es gibt) heideggeriano alcanza una enorme riqueza que, precisamente al vestirse de omnisciencia, pone de manifiesto lo limitado en nuestra capacidad de aprehender la complejidad del ser.

En efecto, los tiempos lúdicos juguetean a reproducir o a citar con parámetros distópicos, utópicos o historiográficos la propia historia de la humanidad y de sus sistemas de creencias. Seccionando épocas o gestas concretas - los Civilization diseñados por Sid Meier - o intentando atravesar hipotéticas fabulaciones mitológicas —de Populous (Bullfrog, 1989) a Godus (22 Cans, 2013)—, todos los videojuegos acaban por poner de manifiesto que su diseño parte de una dimensión antropológica — esto es, de nuevo, heredada de la modernidadque entiende espacio y tiempo como variables únicamente humanas y a las que intenta encerrar en una diégesis más o menos controlada. El problema, por supuesto, es que el asombro ante el gesto divino que se supone que ejercita el Dasein virtual - pongamos por caso: crear una montaña, o destruir un pueblo enemigo por su pura voluntad o, en el límite, crear un ente que en el mundo virtual queda específicamente conectado como ser humano- no se puede enmarcar tan fácilmente. Dicho con mayor claridad: ¿y antes del comienzo del mundo virtual? ¿Y qué ocurre más allá, una vez que se ha acelerado el tiempo de juego —un dios, parecen sugerir las mecánicas, está demasiado aburrido como para contemplar los entresijos de nuestra acción en tiempo real-y se completan todas y cada una de las acciones posibles en el mundo? 


\section{Ser-en-el-mundo-virtual}

Hemos dejado para el final la que, a nuestro juicio, es la aportación principal del primer Heidegger al actual diseño de mundos virtuales: la manera en la que las interacciones de cualquier videojuego son, paradójicamente, una reescritura técnica del ser-en-el-mundo que el filósofo situó como un "constitutivo fundamental" (Grundverfassung) de la existencia. En efecto, al entender el mundo como existenciario en oposición a las habituales lecturas categoriales, se está preguntando precisamente por la cotidianidad de los gestos y los afectos (Rodríguez, 2006, pp. 74-75), esto es, por la manera en la que se generan interacciones, estados de entes $y$, entre ellos, cambios provocados por los usos de los mismos.

Atendiendo al Dasein virtual, parece claro que su ser-en-el-mundo únicamente puede ser pensado como inserto en una constelación de entes en los que emerge su experiencia particular. De nuevo, debemos subrayar que no se trata del videojugador - cuyo ente privilegiado sería el teclado, el pad, o los dispositivos de los que se vale para responder a una serie de estímulos objetuales, esto es, exteriores a su ser sujeto-, sino a la propia instancia experimentable/existenciable ofrecida por los diseñadores videolúdicos. El Dasein virtual debe — como veíamos a partir de la angustia- preguntarse por la existencia en relación a la nada que bordea su mundo y, lógicamente, a partir de los desgarros de su diseño.

El mundo, en tanto existenciario virtual, sirve como contenedor de posibilidades que se van actualizando constantemente. Los entes intramundanos se aparecen a nosotros en un orden que viene dado por la pragmaticidad (Zeughaftigkeit) y, por lo tanto, únicamente puede ser pensado en la manera en la que nos hacemos con ellos, en nuestro encuentro y trato con ellos. Ahora bien, el diseño de la existencia en el videojuego no 
viene dado tanto por la gestión que de los útiles se hace en la narrativa estructurada, sino por la manera en la que las interacciones se ordenan mediante dos parámetros típicamente heideggerianos: los plexos de entes o todo-de-útiles (Zeugganzen) y, en un segundo nivel, el complejo término Bewandtnis que aquí, siguiendo la traducción de Alejandro Escudero (2017, p. 158), denominaremos disposición funcional.

El primer rasgo hace referencia a la conexión espacial y temporal que une a unos entes con otros en la construcción de la actividad cotidiana. Se podría decir que nada hay menos cotidiano que muchas de las aventuras que se despliegan en las narrativas estructuradas de un videojuego. Sin embargo, en el momento en el que bajamos al diseño de plexos de entes, no es fácil ver que las ordenaciones entre mundos virtuales aparentemente divergentes entre sí comparten un inevitable aire de familia, algo así como una suerte de mundanidad de las mecánicas, por Ilamarlo de alguna manera. Un buen ejemplo sería Shadow of the Tomb Raider (Crystal Dynamics/Eidos Montréal, 2018), cuya localización y diseño aparentemente nada tiene de cotidiano. Sin embargo, en el momento en el que estudiamos la disposición de los todode-útiles, la cosa comienza a depurarse: las paredes están dispuestas para ser escaladas, por lo que se dispone de un piolet, que a su vez puede ser usado también para atacar animales o para desmontar puertas. Los animales funcionan como amenazas, pero también son proveedores de recursos (huesos, pieles) para fabricar armamentos o vestir a Lara Croft. Lo que queremos proponer es que el diseño independiente de un útil no tiene el menor sentido: el mundo, en tanto existenciario del Dasein virtual únicamente puede ser desvelado por la manera en la que se van encadenando progresivamente las acciones en un aprendizaje paulatino donde los hechos del mundo se despliegan en una conexión experiencial unificada de la que emerge su sentido mismo. 
Valga decir, además, que las torsiones espaciotemporales que propone la narrativa estructurada no hacen sino darnos la razón en el aspecto mismo de la cotidianeidad: cuando jugamos, por ejemplo, los recuerdos de la infancia de Lara en la mansión familiar, podemos comprobar cómo los todo-de-útiles están dispuestos a-la-mano en un armónico juego de resonancias, remembranzas y disposiciones. La liana de la selva es aquí una tubería. La acción de escapar por los tejados de un pueblo en Ilamas o por el techo de cristal de un invernadero no dejan de ser las maneras concretas en las que el mundo se convierte en susceptible de ser experimentado, atravesado. Quizá se entienda ahora mejor lo que sugeríamos hace unas páginas a propósito de la angustia como bug: en los videojuegos los entes pueden romperse fingiendo la experiencia del mundo real — pongamos por caso: una pistola puede dejar de disparar o una pasarela puede dejar de permitir el paso entre dos pasos elevados_, sin embargo, la verdadera ruptura de sentido — lo que Heidegger denominaba, en este contexto, "perturbación" (Störung) en el sentido marcado en el parágrafo 16 de Ser y tiempo- únicamente tiene lugar en el bug, allí donde se rompen los plexos y emerge la angustia.

Sin salir de Shadow of the Tomb Raider, parece claro que se puede establecer, siguiendo la teorización del todo-de-entes, la idea de que el diseñador no encara la creación de objetos o de niveles, ni siquiera de personajes, sino antes bien, la compleja suma de plexos que remiten unos a otros y que acaban funcionando como una remisión, un entramado, un entorno mundano. La liana remite al cuerpo de Lara, que a su vez remite a la disposición del río y a la amenaza de ser destruido por él, todo lo que finalmente, reunido, remite en última instancia al Dasein virtual y su hipotético ser-en-el-mundo-Virtual.

Lo que nos lleva a la idea final de la Disposición Funcional (Bewandtnis) como clave absoluta del diseño videolúdico. En efecto, la idea clave que hace avanzar los plexos no es únicamente la de su pragmatismo, sino también la 
de su encaje o su ordenación. Es la disposición — esto es, la colocación de los entes para generar la simulación de un cierto tiempo y un cierto espacio, así como unas ciertas interacciones - funcional - con vistas a un correcto despliegue de un desvelamiento del mundo-, donde realmente se anuda toda la complejidad de la existencia virtual. De la manera en la que se ordenan en torno a su función, los diferentes entes hacen emerger el sentido, o mejor dicho, la significatividad (Bedeutsamkeit) del juego. Sin duda, es un error tentador querer posicionar algún tipo de rasgo dominante por encima de la Bewandtnis - la trama, la empatía con los personajes, la manera en la que se gestionan las curvas de dificultad o la novedad de las mecánicas de interacción o de sus límites-, cuando lo que realmente es clave para crear una experiencia poderosa es esa disposición, ese encaje de los entes que acaba configurando el mundo. Diseñar "disposiciones funcionales" es desplegar la composición de las posibles remisiones que sufren y experimentan los entes a partir del gesto cotidiano de juego. Después de todo, Heidegger sugirió la hermosa metáfora del Spielraum entfernten "Umwelt" (Heidegger, 1977, p. 143) ("espacio de juego ${ }^{7}$ del mundo circundante") cuando reflexionó, precisamente, sobre nuestra manera de orientarnos y de comprender nuestra espacialidad. Y después de todo, esta era la clave para entender cualquier mundo: la suma de significatividad (Bedeutsamkeit) y disposición funcional (Bewandtnis).

\section{Conclusiones y futuras líneas de desarrollo}

Hemos esbozado, de manera muy somera, la problemática que emerge en el intento de pensar el diseño de mundos virtuales desde las herramientas del primer Heidegger. Se trata de un paso necesario para acometer una visión postmetafísica de los procesos que componen el universo ludológico, esto es, de

\footnotetext{
${ }_{7}^{7}$ Jacinto Rivera propone la traducción "campo de juego" por "spielraum" (Heidegger, 2009, p. 127), que pareciéndonos indudablemente interesante, quizá permite perder algunos matices interesantes para nuestro trabajo. Merece la pena señalar que dicho concepto —en el contexto de la obra de Walter Benjamin y su relación con los mundos virtuales - ya ha sido trabajado con anterioridad (Jayemanne, 2003).
} 
los que intentan partir de una diferenciación idealista, heredada del pensamiento de la modernidad —y, muy concretamente, de la noción cartesiana del sujetoque pueda trascender, de alguna manera, la discutible división entre el diseño ludonarrativo aplicado a tramas, objetos y/o mecánicas. Muy al contrario, la reivindicación de la mundaneidad o del mundo entendido como existenciario puede modificar, de manera muy positiva, la concepción y el análisis mismo de los procesos de significación videolúdicos. A continuación (Figura 1), ofrecemos una breve sistematización esquemática de nuestro recorrido:

Enfoque tradicional: Diseño ludonarrativo convencional (tramas, objetos, mecánicas)

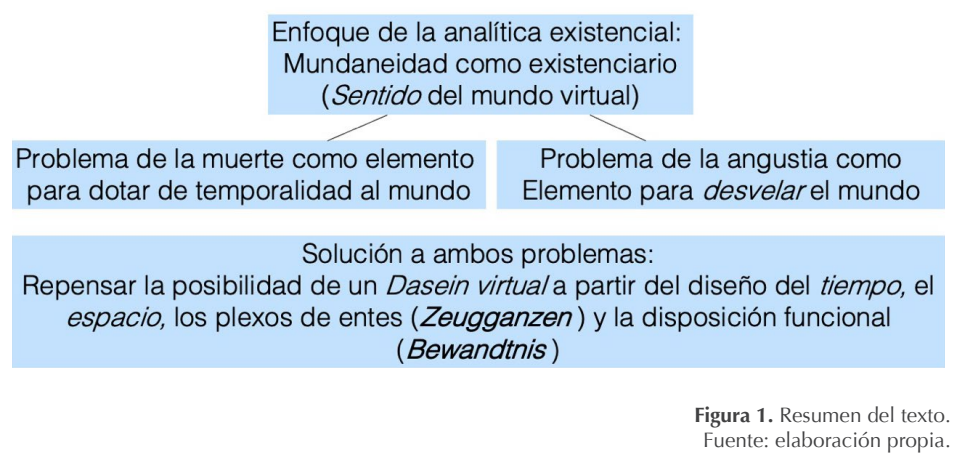

Como se puede apreciar, pretendemos contribuir al desarrollo de la ludología tradicional mediante la aplicación de la analítica existencial. A partir de dicho movimiento, surgen dos problemas clave: el de la muerte (como elemento capaz de dar temporalidad al mundo virtual) y el de la angustia (como elemento clave para su desvelamiento). En ambos casos, el sentido se construye para el Dasein virtual a partir del diseño del juego en las variables de espacio, tiempo e interacción pragmática de entes. 
No obstante, hemos sido conscientes de los muchos problemas que nos surgen al paso. El carácter indudablemente conservador del pensamiento de Heidegger y sus más que preclaros reproches hacia una cierta concepción de la técnica (Heidegger, 1995), así como el ya citado rechazo a la cibernética aconsejan prudencia a la hora de valerse de algunas herramientas, máxime cuando en el centro mismo del proyecto de Ser y tiempo se nos pone en guardia tanto de las interpretaciones "existencialistas" como de la tentación de acercarse al estudio de las "ontologías regionales" sin haber fundamentado bien las raíces de una analítica existencial de largo recorrido. El estudio del diseño de videojuegos, por el momento, no deja de ser una "ontología regional", si bien es cierto que su constante complejización y la riqueza de sus estrategias discursivas siguen sirviendo, año tras año, para que se enriquezca y se problematice nuestro propio pensamiento ontológico. Sin embargo, creemos que hay una cierta riqueza incluso en aquellos dos puntos base ciegos que hemos localizado - los problemas de diseñar muertes ludoficcionales e incluso, mejor aún, la presencia clave de la angustia/bug como desveladora de la nada que se acuna en el mundo virtual-.

Por mucho que en la segunda parte hayamos intentado proponer los puntos fuertes de ese hipotético ser-en-el-mundo-virtual, somos conscientes de que más allá de la significatividad, del uso de plexos de entes e incluso de la Bewandtnis quedan amplísimos y muy estimulantes terrenos para despejar. Citemos apenas dos de ellos. De una manera u otra, y aunque no tengamos aquí tiempo para desarrollar la complejidad de esta idea, el remitir de los entes al mundo es aprehensible en los cuatro tipos de remisión del ente heideggeriana (um-zu, wozu, dazu y umwillen). Cada uno de ellos comparece de manera diferente y exige un diseño distinto, máxime cuando nos topemos con ese problema mayor que es el ser-con-los-otros (Mitsein), cuya importancia en nuestro campo es cada vez mayor gracias al auge de los llamados mundos abiertos y las notabilísimas modificaciones que estos tipos de juego implican en el diseño de videojuegos. El partir de la cotidianeidad para ser uno más —un Dasein entre los otros- 
acaba conduciendo a Heidegger a ciertas posiciones de extrema complejidad que pasan por la crítica del gregarismo, la falsedad de las masas y el desprecio explícito de las industrias culturales (Rodríguez, 2017a), y terminan desplomándose en el ideológicamente más que discutible parágrafo 74 de Ser y tiempo. El pensamiento de Heidegger, como reconocen incluso sus más entregados hagiógrafos, no deja de tener un marcado núcleo nacionalista (Conche, 2006) que es del todo incompatible con mundos diseñados precisamente en busca de una internacionalidad, un encuentro virtual donde avatares de todo el mundo puedan reunirse para generar modos de interacción.

Esto nos lleva, finalmente, al segundo terreno que merecería la pena explorarse. Como es bien sabido, el Heidegger posterior a la Kehre modificó la pregunta por el sentido del ser hacia la problemática por la Verdad del ser. La imposibilidad de terminar las cuatro secciones que deberían componer Ser y tiempo en su forma final (Von Herrmann, 2013) dan buena cuenta de las dificultades experimentadas ante el proyecto total de la analítica existencial y de la necesidad de reenfocar algunos puntos clave. Uno de ellos, sin duda, es la intuición de que tras la superposición de "plexos de entes" marcados por su capacidad de uso, el mundo acababa necesariamente reducido a una existencia pragmática. La primacía del uso, por encima de valores propiamente artísticos, poéticos o incluso sensuales — que sí que serán sobradamente desplegados en el segundo Heidegger - acababa generando una disposición parcial, sesgada, incompleta de lo que podría ser la ek-sistencia.

De aquí que, finalmente, si decidimos aproximarnos a los videojuegos desde una mirada compatible con la filosofía del arte $-\mathrm{y}$ la complejidad y belleza que reside en su diseño, así parece recomendarlo—, sea necesario también poner en valor una pregunta que no gire únicamente en torno a cómo se experimenta ese mundo, sino también a qué mundo virtual queda abierto en el ejercicio mismo del diseño. 


\section{Referencias}

Conche, M. (2006). Heidegger en la tormenta. Melusina.

Contreras, F. R. (2019). Estudio filosófico sobre la mirada estética en el diseño. Kepes, 16(19), 11-38.

Cremin, C. (2016). Exploring Videogames with Deleuze and Guattari: Towards an affective theory of form. Routledge.

Descartes, R. (2011). Meditaciones metafísicas. Gredos.

Dreyfus, H. L. (1992). What Computers Still Can't Do. The MIT Press.

Eilenberger, W. (2019). Tiempo de magos: La gran década de la filosofía (1919-1929). Taurus.

Escudero, A. (2013). El tiempo del sujeto: Un diagnóstico de la crisis de la modernidad. Arena Libros.

Escudero, A. (2017). Heidegger en el laberinto de la modernidad. Arena Libros.

Fernández, J. (2015). Pixelar a Platón. Micromegas.

Frasca, G. (2001a). Ephemeral Games: Is It Barbaric to Design Videogames after Auschwitz? Cybertext Yearbook 2000, 172-182.

Frasca, G. (2001b). Rethinking agency and immersion: video games as a means of consciousnessraising. Digital Creativity, 12(3), 167-174.

Gallastegui, S. (2018). Inmersión y emersión en los juegos digitales. Un modelo de análisis. ICono14, 16(2), 51-73.

Gil, S. y Rodríguez, A. (2017). Y seréis como Dios: la construcción de divinidades ludoficcionales en el contexto transhumanista. Icono14, 15, 211-234.

Heidegger, M. (1977). Gesamtausgabe. Band 52. Sein und Zeit. Vittorio Klostermann.

Heidegger, M. (1995). Caminos de bosque. Alianza Editorial.

Heidegger, M. (1999). Introducción a la filosofía. Cátedra.

Heidegger, M. (2000). Tiempo y ser. Tecnos.

Heidegger, M. (2002). Interpretaciones fenomenológicas sobre Aristóteles. Indicación de la situación hermenéutica. Informe Natorp. Trotta.

Heidegger, M. (2005). La idea de la filosofía y el problema de la concepción del mundo. Herder. 
Heidegger, M. (2009). Ser y tiempo. Trotta.

Heidegger, M. (2013). Seminarios de Zollikon. Herder.

Husserl, E. (1962). Ideas relativas a una fenomenología pura y una filosofía fenomenológica (Libro 1). Fondo de Cultura Económica.

Jayemanne, D. (2003). Spielraum: games, art and cyberspace. Melbourne International Digital Arts and Culture Conference, 1.

Jenkins, H. (2004). Game design as narrative architecture. En N. Wardrio-Fruin y P. Harrigan (Eds.), First person: new media as story, perfromance and game (pp. 118-130). The MIT Press.

Juul, J. (2013). The Art of Failure: An Essay on the Pain of Playing Video Games. The MIT Press.

Lewis, C., Whitehead, J. y Wardrip-Fruin, N. (2016). What went wrong: a taxonomy of video game bugs. ICSE '16: Proceedings of the 38th International Conference on Software Engineering Companion, 108-115.

Leyte, A. (2005). Heidegger. Alianza Editorial.

Loriguillo-López, A. y Sorolla-Romero, T. (2015). "Vive, muere, repite": El blockbuster ante el desafío interactivo. Fonseca, Journal of Communication, 11, 118-132.

Losada, R. (2014). La tecnología 3D como herramienta para explorar los escenarios arquitectónicos contemporáneos. Atalante, 17, 23-29.

McHale, B. (1987). Postmodernist fiction. Routledge.

Michaildis, L., Balaguer-Ballester, E. y He, X. (2018). Flow and immersion in video games: The aftermath of a conceptual challenge. Frontiers in Psychology, 9.

Monchán, J. (2015). Emergencia en el apocalipsis zombi. Mecanismos para la creación de narrativas emergentes en DayZ. adComunica. Revista Científica de Estrategias, Tendencias e Innovación en Comunicación, 9, 185-192. http://dx.doi.org/10.6035/2174-0992.2015.9.12

Navarrete, J. L., Pérez, J. P. y Gómez, F. J. (2014). El pensamiento abductivo como fundamento ontológico de los videojuegos. Icono14, 2, 416-440.

Navarro, V. (2016). Libertad dirigida: Una gramática del análisis y diseño de videojuegos. Shangrila.

Navarro, V. (2019). Ser todo, ser nada: La subjetividad en el videojuego más allá del avatar. Tropelías, 31, 156-173. 
Pardo, J. L. (2004). La Regla del juego: sobre la dificultad de aprender filosofía. Galaxia Gutenberg.

Pérez, Ó. (2012). El Lenguaje videolúdico: análisis de la significación del videojuego. Lartes.

Planells, A. J. (2015). Videojuegos y mundos de ficción. Cátedra.

Portillo, J. (2017). Ontología, funciones y discurso en el videojuego. Revista Humanidades, 7(1), $1-22$.

Ramírez, M. del M. y Navarrete-Cardero, L. (2017). Experiencias innovadoras en dispositivos interactivos aplicados a los videojuegos: el caso de Oculus Rift. AdComunica. Revista Científica de Estrategias, Tendencias e Innovación En Comunicación, 13, 223-242.

Ramírez, M. T. (2008). Intencionalidad y virtualidad: Merleau-Ponty filósofo de la realidad virtual. Investigaciones Fenomenológicas, 1, 223-246.

Rodríguez, C. M. y Martínez, H. F. (2019). Dimensiones virtuales de la ciudad: apropiación urbana mediada por el uso de la aplicación digital Pokemon Go! Kepes, 19, 317-345.

Rodríguez, R. (2006). Heidegger y la crisis de la época moderna. Editorial Síntesis.

Rodríguez, A. (2017a). El desprecio, la técnica y el lenguaje: sobre el rechazo de Heidegger a la expresión cinematográfica. Cultura, Lenguaje y Representación, 18, 27-43.

Rodríguez, A. (2017b). La nada como categoría ontológica en el videojuego. Análisis de Sad Satan. Fonseca, Journal of Communication, 14, 203-214.

Siabra, J. A. (2012). Bosquejo de una metafísica del videojuego. Círculo Rojo.

Trilles, K. P. (2009). Fenomenología y realidad virtual: el reto de un nuevo mundo. Arbor, CLXXXV(736), 427-435. http://doi.org/10.3989/arbor.2009.i736.291

Vattimo, G. (1986). Introducción a Heidegger. Gedisa.

Von Herrmann, F. W. (2013). La "segunda mitad" de Sery Tiempo. Sobre los problemas fundamentales de la Fenomenología de Heidegger. Lógica y verdad en la Fenomenología de Heidegger y de Husserl. Trotta.

Cómo citar: Rodríguez Serrano, A., Martín Núñez, M. y García Catalán, S. (2021). Diseñar mundos virtuales: límites y hallazgos de la analítica existencial como ontología del videojuego. Revista KEPES, 18(24), 233-259. https://doi.org/10.17151/kepes.2021.18.24.9 